\title{
Sexualidad y alteridad: argumentos del conservadurismo religioso cordobés contra el matrimonio "igualitario"
}

\author{
José Manuel Morán Faúndes \\ Doctor en Estudios Sociales de América Latina (Universidad Nacional de Córdoba) \\ Becario CONICET en la Universidad de Córdoba \\ jmfmoran@gmail.com
}

\begin{abstract}
Resumen En 2010 Argentina aprobó la ley que modificó el Código Civil, permitiendo a parejas del mismo sexo contraer matrimonio. Durante el período de discusión legislativa, diversos sectores conservadores esgrimieron argumentos públicamente para evitar la aprobación de la ley. En Córdoba, la movilización de estos fue ampliamente visible, y sus discursos circularon por diversos espacios públicos, alcanzando notoriedad incluso a nivel nacional. Tomando esto en consideración, el presente artículo analiza los argumentos esgrimidos por el movimiento conservador religioso cordobés, poniendo especial énfasis en las construcciones de la alteridad sostenidas desde estos lugares a través de las ideas de nación, familia y naturaleza. A partir de estos ejes, se consideran las articulaciones argumentales que buscaron ligar las expresiones no heterosexuales con la idea de un Otro, entendido como antítesis de lo natural y de la identidad nacional.
\end{abstract}

Palabras-clave: sexualidad, matrimonio, naturaleza, nación, Córdoba.

$\mathrm{E}$ L IS De Julio De 2010 el Congreso de la Nación de Argentina aprobó la ley que modificó el Código Civil instituyendo el denominado matrimonio "igualitario". ${ }^{1}$ El proceso previo a la sanción de la ley estuvo caracterizado por un intenso debate y movilización a nivel nacional, donde los distintos sectores favorables y contrarios a la iniciativa legislativa promovieron distintas acciones de incidencia política, esgrimiendo a su vez diversos argumentos en torno a la legitimidad o no de legalizar los matrimonios entre personas del mismo sexo.

A lo largo de los meses que antecedieron a la discusión legislativa, el sector opositor al matrimonio "igualitario" se organizó a lo largo y ancho del país a fin de manifestarse públicamente y realizar un intenso lobby para frenar la modificación del Código Civil. Dentro de este proceso, Córdoba en particular fue una provincia en la cual este activismo adquirió un gran protagonismo, siendo su capital la primera ciudad

\footnotetext{
1. Escribo la palabra "igualitario" entre comillas en el presente artículo, ya que considero que la nueva posibilidad que abre la ley a las parejas del mismo sexo a contraer matrimonio no le otorga una condición de igualdad plena a esta institución. Esto debido a que aún la ley no permite que las personas se casen según su identidad de género autopercibida, discriminando con esto a las personas trans, además de otras formas de expresión de las relaciones afectivas que siguen excluidas del matrimonio, como las relaciones de tres o más personas, entre otras.
} 
del país donde se organizó una marcha en contra del matrimonio "igualitario".

Tanto en la convocatoria y coordinación de esta marcha, como en otras actividades públicas orientadas a incidir en el rechazo a la sanción de la ley, participaron una importante diversidad de organizaciones locales. La jerarquía de la Iglesia católica, algunas iglesias evangélicas, sectores vinculados con partidos políticos y algunas asociaciones civiles autodenominadas "provida", como Portal de Belén, Nuevo Espacio, Programa Nazaret y Jóvenes Autoconvocados por la Vida, tuvieron un rol protagónico en este contexto.

Pese a la gran diversidad de actores que constituyeron este sector, su trabajo conjunto logró establecer ciertas estrategias y discursos relativamente articulados que fueron centrales en la oposición al matrimonio "igualitario" en la provincia de Córdoba, repercutiendo también luego a nivel nacional. Dichos discursos recurrieron a nociones específicas acerca de la cultura argentina, la nación, la familia y la naturaleza humana, que resultaron centrales en los argumentos opositores a la iniciativa legislativa.

Tomando esto en consideración, en el presente artículo analizo los argumentos esgrimidos por los/ as activistas cordobeses/as opuestos/as a la modificación de la ley en Argentina, poniendo especial énfasis en las construcciones de la alteridad sostenidas desde estos lugares a través de las ideas de nación, familia y naturaleza, y su relación con la sexualidad. Para dichos efectos, recurrí a tres fuentes de información empírica: entrevistas en profundidad realizadas a miembros/as de organizaciones civiles del sector opositor al matrimonio "igualitario", ${ }_{2}$ material impreso y on-line producido por dichos sectores en torno al tema, y la versión taquigráfica de las intervenciones realizadas por los mismos ante la Comisión de Legislación General del Senado de la Nación en Córdoba. ${ }^{3}$

El presente trabajo se organiza en tres secciones. En la primera presento algunas características generales del activismo cordobés opuesto al matrimonio "igualitario", a fin de contextualizarlo como movimiento político articulado. En las siguientes dos secciones analizo sus argumentos considerando específicamente dos ejes analíticos: a) la idea de una naturaleza humana como modeladora del binomio heterosexual/no-heterosexual, y b) su articulación con las nociones de familia y nación.

Estos dos ejes analíticos no pretenden ser exhaustivos, sino que tienen como fin analizar especí- ficamente dos elementos que resultaron centrales en los argumentos evidenciados en el espacio público en contra del matrimonio "igualitario" durante el período de discusión pública de la ley, y que constituyen líneas relativamente claras de construcción de una oposición Nosotros/Otros que resulta medular en el discurso de este activismo.

\section{El movimiento opositor de Córdoba}

El movimiento cordobés opuesto a la aprobación del matrimonio "igualitario" no puede ser comprendido como un actor monolítico y homogéneo. Por el contrario, como movimiento está conformado por múltiples organizaciones, cuyos fundamentos y campos de acción si bien presentan importantes puntos de encuentro, también difieren en algunos aspectos que es necesario considerar.

Las trayectorias de las organizaciones que conforman este activismo son disímiles. Algunas de ellas presentan una larga historia, como la Asociación Civil Portal de Belén que nace en 1991, o la misma Iglesia católica cordobesa, mientras que otras tienen una historia de vida más corta, como las organizaciones Jóvenes Autoconvocados por la Vida y Plan 1.5, con menos de diez años de existencia. Respecto de las asociaciones civiles, su trabajo se ha centrado fuertemente en la temática del aborto, ejerciendo actividades orientadas a evitar su promoción y legalización. Desde principios del nuevo milenio, las labores de algunas organizaciones se abocaron además a la oposición del reparto de la anticoncepción hormonal de emergencia en la provincia, por considerar que esta vulneraba el principio defendido por ellas acerca de la inviolabilidad de la vida humana desde el momento de la concepción.

En este sentido, aunque sus argumentos tradicionales siempre han girado en torno a la noción de la familia heterosexual y conyugal, el trabajo de estas agrupaciones no se había focalizado tan fuertemente en oponerse a las relaciones no heterosexuales hasta la puesta en discusión del matrimonio "igualitario" durante el primer semestre del 2010, donde este último tema desplazó al aborto como centro de su interés.

Desde el punto de vista de sus acciones concretas, estas son diversas, e incluyen desde intervenciones en ámbitos educativos orientadas a transmitir su discurso

\footnotetext{
2. Fueron realizadas cinco entrevistas en profundidad a líderes del movimiento en Córdoba, y cuatro entrevistas complementarias a miembros/ as de organizaciones de las provincias de Buenos Aires y Mendoza. Agradezco profundamente el trabajo de transcripción de algunas de estas, realizado por Carolina Sánchez.

3. Dicha sesión se llevó a cabo el día 23 de junio de 2010, y fue parte de una serie de sesiones en donde el Congreso de la Nación se trasladó a distintas provincias del país a fin de escuchar los argumentos de los diversos sectores a favor y en contra del matrimonio "igualitario". La versión taquigráfica de la sesión en Córdoba está disponible en <http://www.prensalegiscba.gov.ar/img/notas/adjunto-1207.doc>.
} 
centralmente a alumnos/as de Educación primaria y secundaria, hasta el lobby político y la presentación de recursos judiciales para evitar el avance de la agenda de los derechos sexuales y reproductivos. En esta última línea, por ejemplo, se orientaron los recursos judiciales presentados por el Portal de Belén y por la Asociación Civil Mujeres por la Vida solicitando impugnar la decisión del Estado de entregar gratuitamente la anticoncepción hormonal de emergencia. Así, tal como ha destacado la literatura latinoamericana que ha estudiado a estos sectores, el trabajo de estas organizaciones se ha volcado fuertemente al ámbito del derecho, así como a la producción académica, la educación y la incidencia política, entre otras (Rostagnol, 2010; Mujica, 2007; Vaggione, 2009a; Dides, 2006). Por otro lado, organizaciones como Jóvenes Autoconvocados por la Vida han desarrollado desde sus inicios estrategias de incidencia en ámbitos educativos, realizando charlas informativas y talleres con jóvenes de colegios de la provincia de Córdoba. Otras en tanto, como el Programa Nazaret, desarrollan labores asociadas a la acogida de niños y niñas internados/as en institutos estatales de menores, convocando a familias para que los/as acojan luego en adopción. Portal de Belén, a su vez, posee y administra casas en donde atiende y aloja a mujeres embarazadas en situación de vulnerabilidad, con el objetivo de evitar que aborten. De este modo, los campos de acción donde trabajan estas organizaciones son diversos, lo que les otorga una importante capacidad de despliegue e intervención política y social.

No todas las organizaciones han tenido la misma fuerza y visibilidad, pero en su actuar han conformado redes de cooperación desde las cuales han logrado articular acciones conjuntas que les han otorgado una mayor fuerza como movimiento. Así, por ejemplo, las presentaciones judiciales contra la anticoncepción hormonal de emergencia han sido trabajadas conjuntamente por los/as miembros/as de las organizaciones Mujeres por la Vida y Portal de Belén. Esta última, en conjunto con Jóvenes Autoconvocados por la Vida, ha coordinado además charlas dictadas en distintos colegios de la provincia sobre la temática del aborto. A su vez, Jóvenes Autoconvocados por la Vida realiza actividades conjuntas con la Asociación Civil Hogar de María que trabaja para evitar que mujeres en situación de vulnerabilidad aborten, tarea similar a la que realiza el Portal de Belén y la organización de jóvenes Plan 1.5.
La red es amplia, y su articulación no solo comprende asociaciones civiles, sino también iglesias (católica y evangélicas, ${ }^{4}$ principalmente), sectores privados que aportan recursos desde el voluntariado, y algunos sectores o personalidades vinculadas con el ámbito de la política. En este último plano, por ejemplo, miembros de la organización Portal de Belén han tenido un rol activo en la conformación de partidos políticos que han participado en las últimas elecciones legislativas de Córdoba. Uno de los fundadores de Portal de Belén, Aurelio García Elorrio, fue electo así legislador provincial en las elecciones de 2011, un año después de la aprobación del matrimonio "igualitario", representando al partido Encuentro Vecinal Córdoba. Asimismo, el ex diputado provincial por la Unión de Centro Democrático (UCD), Rodrigo Agrelo, fue uno de los principales rostros del movimiento en los medios de comunicación durante el debate en torno al matrimonio "igualitario".

Ante esta multiplicidad de actores y campos de acción, algo que quizá caracteriza a todo el movimiento cordobés contrario al matrimonio entre parejas del mismo sexo, es el carácter "conservador" que puede imputársele (Mujica, 2007; Dides, 2006). La pertinencia de este término para caracterizar a estos sectores de una manera general, aunque no necesariamente exhaustiva, se remite a que su lucha se ha fundado en lograr la preservación de normas sexuales y de género tradicionales, ancladas en el paradigma de la heterosexualidad reproductiva. ${ }^{5}$ Como indica Juan Marco Vaggione (2010), la noción de conservadurismo, aunque ambigua y poco clara, apela al aspecto ideológico de un activismo que se ha posicionado como contrario al avance de la agenda de los derechos sexuales y reproductivos no solo en Córdoba y Argentina, sino en América Latina en general, intentando conservar y proteger un orden sexual que se considera amenazado por el feminismo y el movimiento por la diversidad sexual.

Pero además del carácter conservador de este movimiento, parte de la literatura ha tendido a destacar también una fuerte impronta religiosa que puede ser comprendida como parte constituyente del mismo (Vaggione, 2005; Rabbia e Iosa, 2011). Bien es sabido el rol que jugó tanto la jerarquía católica como algunas iglesias evangélicas en la oposición al matrimonio "igualitario" en Córdoba y en Argentina en general, así como algunas asociaciones civiles manifiestamente ligadas a una u otra religión. Otras organizaciones,

\footnotetext{
4. No todas las iglesias evangélicas presentan posturas opuestas a la agenda de los derechos sexuales y reproductivos. El denominado "polo histórico liberacionista" (Wynarczyk, 2006), ha presentando posturas favorables a muchas de las demandas feministas y de la diversidad sexual (Jones, Azparren y Polischuk, 2010).

5. Sin embargo, el término no deja de resultar problemático. Desde un punto de vista crítico de la teoría queer, el matrimonio "igualitario" constituye igualmente una institución que esencializa identidades y contribuye a la homo y lesbonormatividad (Preciado, 2003; Butler, 2006). Así, los sectores que defienden el matrimonio "igualitario" podrían también ser considerados como conservadores. Sin embargo, y teniendo en cuenta sus limitaciones, utilizo el término para referirme al movimiento opositor al matrimonio "igualitario", a falta de un concepto más preciso.
} 
en cambio, que también formaron parte de este movimiento, tendieron ( $\mathrm{y}$ aún lo hacen) a presentarse como instituciones sin una afiliación confesional particular, pero con argumentos públicos coincidentes a los utilizados desde las jerarquías de la Iglesia católica y de algunas iglesias evangélicas. Así, aunque sin mencionar la figura de Dios ni recurrir a la teología para articular sus argumentaciones, algunas organizaciones opositoras al matrimonio "igualitario" (y también a la legalización del aborto y la anticoncepción hormonal de emergencia, a la distribución libre y gratuita de anticonceptivos, a la educación sexual laica e integral, entre otras cosas) asumen una posición aparentemente secular, pero que coincide plenamente tanto con la postura de las jerarquías de las iglesias conservadoras respecto a temas de sexualidad y reproducción, como con algunos de sus principales argumentos vinculados a estas temáticas.

¿Cómo es posible entonces comprender esta confluencia entre lo religioso y lo secular dentro del movimiento contrario al matrimonio "igualitario"? Para esto, resulta útil recurrir a la noción de "secularismo estratégico" acuñada por Vaggione (2005), esto es, la idea de que la adopción de una posición secular responde a una estrategia de algunos organismos religiosos ${ }^{6}$ (que pueden presentarse o no como confesionales en el espacio público) para lograr una mayor incidencia en el debate político vinculado con el rechazo a la agenda de los derechos sexuales y reproductivos. Según el autor, la utilización de discursos y estrategias seculares por parte de algunas organizaciones religiosas se funda en una suerte de reacción de estos sectores frente al avance de la agenda de los derechos sexuales y reproductivos, a partir de la cual se activa una reducción al mínimo del discurso religioso y una maximización de las argumentaciones científicas y legales con el fin de penetrar espacios que difícilmente podrían ser permeados por un discurso basado expresamente en la fe y los dogmas cristianos. Así, diluyendo las fronteras entre lo religioso y lo secular, el secularismo estratégico le permite al conservadurismo religioso penetrar la esfera de lo político y oponerse en este plano a las agendas feministas y por la diversidad sexual, sin necesariamente desprenderse del dogmatismo que instituye algunas de sus posiciones. ${ }^{7}$

Este ir y venir desde lo religioso a lo secular, le permitió al conservadurismo religioso cordobés entrar en el debate del matrimonio "igualitario" con argumentos que disipaban los discursos vinculados explícitamente con la fe, soslayando además toda crítica orientada a descalificar su postura por ser propia de intereses y posiciones religiosas específicas, y no del bien común de la sociedad. De algún modo, estas formas de incidencia política de la religión que operan desde la sociedad civil permiten discutir las ideas que han asumido a la esfera civil como una arena de irrestricto cuestionamiento hacia las nociones de género y sexualidad defendidas por las iglesias más conservadoras (Rosado-Nunes, 2004; Becerra dos Santos, 2004).

\section{Lo natural y el Otro: hacia una ecología de la alteridad}

A lo largo de la discusión en torno al matrimonio "igualitario", prácticamente la totalidad de los discursos esgrimidos por el conservadurismo religioso cordobés (y el argentino en general) se fundaron sobre la idea de una sexualidad "natural" y otras múltiples sexualidades consideradas contrarias a la naturaleza. Pero, ¿qué es lo natural para estos sectores? ¿Cómo articulan la idea de lo natural con la sexualidad? ¿Qué implicancias tiene esta articulación para las expresiones sexuales alejadas de la heterosexualidad? En lo que sigue, intentaré esbozar algunas respuestas para estas preguntas basándome en materiales relevados durante la discusión pública en torno al matrimonio "igualitario" en Argentina.

El movimiento conservador religioso cordobés asume en su discurso la existencia de una verdad única e innegociable. Esta verdad estaría ligada a la "naturaleza humana", desde donde se desprenderían los valores universales que debiesen servir de criterio base para la acción moral. La idea de una naturaleza humana, sostenida fuertemente desde el catolicismo (Ratzinger, 2008), ha sido también adoptada desde los bloques conservadores evangélicos, los que en el último tiempo han tendido a acercar su lenguaje a aquel que utiliza la teología católica (Jones, Azparren y Polischuk, 2010). ${ }^{8}$ De este modo, la noción de una naturaleza humana anclada en la idea de una verdad absoluta, es compartida transversalmente por el movimiento conservador religioso. Al respecto, un activista del movimiento de Córdoba señala:

6. No todos los sectores religiosos deben ser considerados como parte del activismo conservador opuesto a los derechos sexuales y reproductivos. Algunos de hecho apoyaron la iniciativa legislativa del matrimonio "igualitario", como fue el caso del sacerdote cordobés José Alessio.

7. La influencia que ha adquirido la religión en el campo de la bioética, y especialmente la católica, es un ejemplo del uso de argumentos seculares para defender la posición de la Iglesia en temas de sexualidad y reproducción. Al respecto, ver Peñas Defago (2010) y Carbonelli e Irrazábal (2010).

8. Lutero como Calvino rechazaban la idea de "lo natural" como aquello que se encontraría libre de corrupción. Por esto, la utilización de la idea de una naturaleza humana por parte de los bloques conservadores evangélicos puede ser interpretada como un acercamiento al lenguaje católico en defensa de una moral sexual conservadora (Jones, Azparren y Polischuk, 2010). 
nosotros optamos por humanizar la cultura y la única fuente, la única forma, es decir, en la historia del pensamiento ha habido distintas corrientes, intentos, yo creo que se ha intentado prácticamente todo, lo único es la naturaleza humana. O sea, el descubrir que hay una naturaleza humana que es distinta a la naturaleza de las cosas, o sea a la naturaleza de los animales e ir descubriendo cuál es la grandeza de esa naturaleza humana, cuales son las condiciones, etcétera, etcétera, y bueno, sacar lo mejor que hay del ser humano (activista movimiento conservador religioso, Córdoba, 2010).

Lo "natural" es entendido como aquello que hace al ser humano ser lo que es. Supone la existencia de una verdad inmutable, anterior a toda cultura o acción humana. Cualquier desviación respecto de lo natural implicaría así un alejamiento inmediato de lo que lo hace ser humano.

En el plano específico de la sexualidad, "lo natural" es asumido por el conservadurismo religioso desde el punto de vista de una naturalidad biológica que determina la configuración binaria del sexo. En otras palabras, el sexo se comprende acá a partir del paradigma biomédico hegemónico (Fausto-Sterling, 2006) que lo circunscribe dentro de los márgenes de un dimorfismo fundado en una estructura binaria de carácter genético, gonadal y genital (Morán Faúndes, 2011).

Sin embargo, esta diferencia fundacional no solo se expresa para estos sectores en una constitución bioanatómica distinta entre ambos sexos, sino además en diferencias psicológicas, perceptivas, afectivas e intelectuales ancladas en los mismos. En palabras de un activista cordobés:

se ha profundizado mucho en todo eso, la diferencia entre varones y mujeres, las diferencias espirituales, las diferencias intelectuales, la forma de pensar, los afectos y hasta hay diferencia en el modo de percibir los colores y eso explica que estamos de modos completamente diferentes varones y mujeres, porque, es que los colores los vemos distintos. [...] Nosotros vemos menos colores y más opacos y las mujeres los ven más vivos. Por eso a nosotros los colores más vivos nos chocan. [...] Y a ellas al contrario les llama poderosamente la atención, bueno todo eso forma parte de la naturaleza humana (activista conservador religioso, Córdoba, 2010).

La naturalidad del sexo binario se apoya en un régimen epistemológico conocido como "realismo", desde donde se asume la existencia de una realidad objetiva independiente del sujeto, una realidad "natural" que lo condiciona como tal, enmarcándolo en un determinado sexo (Halperin, 2004). De este modo, el discurso niega totalmente la posibilidad de cuestionar la verdad esencialista que sostiene la idea de un sexo binario y una identidad de género construida en torno a este, como propone por ejemplo la teoría queer (Butler, 2007). Sirva como ejemplo el comentario de un militante de una organización civil cordobesa:

[Para] mí la realidad es chocante, es chocante en el sentido que es irrefutable, es decir, vos me decís que somos idénticos, bueno mostráme el caso de algún varón que se haya transformado en mujer. No que se haya vestido de mujer, sino que sea una mujer, que piense, que piense como mujer, que sienta como mujer, que ame como mujer, mostráme un caso, si no me podés mostrar ningún caso, bueno, entonces discúlpame, tu teoría no resiste, no resiste ni siquiera un análisis científico (activista conservador religioso, Córdoba, 2010).

De la binaridad de los sexos, se desprende dentro del discurso conservador religioso la noción de una sexualidad igualmente configurada en torno a la naturalidad biológica humana. La orientación del deseo sexual se vincula así en los argumentos conservadores religiosos con el condicionamiento biológico de un sexo binario, especificándose el mandato de consumación de prácticas sexuales únicamente entre personas de distinto sexo. La práctica sexual "natural", en este sentido, es la práctica heterosexual reproductiva. De ahí la calificación "antinatural" o "contranatural" con los que estos sectores tienden a calificar a las sexualidades no reproductivas, y a su inmediato rechazo moral.

Es necesario detenerse en este punto, para dar cuenta de las operaciones discursivas que están detrás de la distinción natural/no-natural. La noción de naturaleza humana remite a la idea de una esencia que delimita las fronteras de lo propiamente humano. Si las expresiones sexuales alejadas de la heterosexualidad son comprendidas como tendencias que van en contra de la naturaleza humana, es decir, de la esencia de lo que constituye al ser humano, esto implica que lo que no es heterosexual se aleja entonces de "lo humano". La lesbianidad, la homosexualidad y cualquier otra expresión sexual o de género que subvierta la heterosexualidad obligatoria (Rich, 1994), no solo representa una forma de sexualidad jerárquicamente inferior respecto de la heterosexualidad (Rubin, 1989), sino que el discurso conservador religioso la sitúa además por fuera de lo reconocible como lo propiamente humano. Las fronteras de lo natural operan como fronteras de lo humano/no-humano.

Al ser comprendida como tendencias contranaturales, las expresiones no heterosexuales son caracterizadas por el conservadurismo religioso como desviaciones o enfermedades, con causas incluso que 
parecieran ser biográficamente identificables en algún episodio concreto de la vida de la persona: un episodio de vida traumático, una conducta "viciosa" o un trastorno psicológico, por ejemplo (Morán Faúndes, 2011). Siendo consideradas como tendencias viciosas o enfermedades, son asumidas también como curables o evitables. Al respecto, un activista del movimiento conservador religioso cordobés declara:

Uno sí puede, en cambio, heredar alguna tendencia, entonces, uno puede heredar alguna tendencia del tipo cleptómana, esa tendencia de quedarse con lo ajeno es una enfermedad eso. Ahora, yo puedo tener una tendencia, si la tendencia yo juro que es mala o entiendo que es mala, yo tengo la tendencia y la reprimo de algún modo. El tipo que es cleptómano lo que tiene que hacer es no robar, entonces, todos tenemos tendencias buenas, en teoría, pero que extralimitadas son un desastre. [...] El homosexual tiene problemas suyos, hay un problema suyo porque efectivamente es una tendencia desordenada que le está dando cause. [...] El homosexual, el homosexual normal, por decirlo, tenés el homosexual que es un chico que ha sido abusado de niño ya tiene un problema, ese tiene un problema. Y el que es un tipo grande que ya ha hecho todo con las mujeres, un promiscuo con las mujeres, que se hartó de las mujeres, y a los sesenta años busca, ese es otro problema, o sea esos son dos puntos (activista conservador religioso, Córdoba, 2010).

Estas afirmaciones hacen posible comenzar a comprender cómo la idea de lo natural opera en el discurso conservador religioso. Sin embargo, parecieran ser aún insuficientes para entender dónde radica la preocupación que manifestaron estos sectores ante la posibilidad de que el derecho reconociese sexualidades que asumen como no naturales. ¿Qué argumentos esgrimió el conservadurismo religioso cordobés para expresar su inquietud ante la idea de que las sexualidades no heterosexuales fueran reconocidas en la institución matrimonial? ¿Por qué, para este movimiento, el Estado cometía un error al ampliar el derecho de matrimonio a parejas del mismo sexo? ¿Por qué debía impedirse este "error" a toda costa? La respuesta a esto se encuentra en una suerte de argumento ecológico que cobró fuerza desde el conservadurismo religioso argentino, y especialmente desde sus organizaciones cordobesas, durante la discusión en torno al matrimonio "igualitario". Este se funda en la noción de la reproducción humana como un mandato obligatorio para la supervivencia de la especie. ${ }^{8}$ Así, asumiendo el hecho de que la supervivencia del ser humano sólo es posible mediante la reproducción del mismo, ${ }^{9}$ estos sectores defienden la obligatoriedad de las prácticas reproductivas heterosexuales como un mandato de conservación de la humanidad. Desde acá, su discurso plantea la imposibilidad de universalizar las conductas no heterosexuales ya que esto condenaría a la especie a su extinción. A partir de esta imposibilidad de universalización, se derivaría el carácter contranatural de la homosexualidad y de cualquier tipo de sexualidad que subvierta la heterosexualidad obligatoria (Rich, 1994):

Si todos los seres humanos fuéramos homosexuales la humanidad acaba en una generación. Entonces, esto no es sostenible, es una conducta que no es socialmente sostenible, puede ser una conducta aislada de una persona, bueno, macanudo, pero sí esto no lo podés universalizar. Si yo no lo puedo universalizar, entonces, va contra la naturaleza humana (activista conservador religioso, Córdoba, 2010).

Llevado a su extremo, el argumento concluye en una posición teleológica que sostiene que la finalidad del matrimonio sería la continuación de la especie humana, lo que impediría denominar con el término "matrimonio" a las relaciones no heterosexuales puesto que estas no estarían orientadas a la reproducción. En este sentido, el discurso del movimiento conservador religioso cordobés tendió a acompañar el término "matrimonio" de una serie de expresiones, tales como "mal llamado" o "pseudo", cuando este era referido a relaciones no heterosexuales, procurando delimitar su significado exclusivamente dentro de las fronteras de la heterosexualidad:

el concepto de matrimonio es el hombre y mujer. ¿¿í? No es entre [dos hombres o dos mujeres], si no hay que cambiarle el nombre, hay que ponerle otro nombre [...]. Si vos igualás el matrimonio es una cuestión de es, si todo es todo, lo que era eso deja de serlo. ¿Me entendés? Si todo es matrimonio, lo que era matrimonio dejó de serlo, o sea, el matrimonio entre el hombre y la mujer, si todo es matrimonio, dejó de ser entre hombre y una mujer, y todo es todo (activista conservador religioso, Córdoba, 2010).

En este punto, el discurso relaciona directamente la noción de "matrimonio" con la de "naturaleza humana". El matrimonio queda así circunscrito por el conservadurismo religioso a las fronteras de "lo na- 
tural" y de "lo humano", estableciéndose los límites del matrimonio donde su exterior constitutivo queda caracterizado por las relaciones no heterosexuales. La naturalidad binaria del sexo que sustenta este discurso establece así una suerte de complementariedad natural entre ambos sexos, cuya consumación queda cristalizada en la institución matrimonial.

De este modo, el matrimonio opera como un dispositivo de división entre sexualidades públicas y privadas, en articulación con la idea de lo natural/ no-natural. Esto debido a que el conservadurismo religioso plantea que su lucha no cuestiona las expresiones no heterosexuales como conductas privadas, sino solo como conductas desplegadas en el espacio público. El impedimento para considerar la apertura del matrimonio a parejas no heterosexuales radica entonces en el carácter público del acto civil matrimonial. El Estado, en este sentido, es considerado por el conservadurismo religioso como una entidad garante de la heterosexualidad obligatoria en pos de la supervivencia de la especie, y el matrimonio es entendido como una institución central para el logro de este objetivo. De este modo, se refuerza la idea de una heterosexualidad natural, aceptable en el espacio público bajo el supuesto de una sexualidad "normal", neutra y sin marcas (Hiller, 2008). Las palabras de un activista conservador religioso cordobés frente a la Comisión de Legislación General del Senado de la Nación, sustentan esta idea:

La conducta homosexual es una conducta gravemente antisocial. Tan antisocial, que amenaza la misma subsistencia de nuestra Argentina. Hoy es una conducta estadísticamente irrelevante, no más del $2 \%$ de la población. Por eso puede ser razonable tolerarla privadamente. Otra cosa es promoverla públicamente, y desde la más tierna infancia. Eso es injusto e irracional, y supone una política socialmente suicida. Es inadmisible (activista conservador religioso, Córdoba, 2010).

La trasgresión de los límites de la heterosexualidad reproductiva desatan en el conservadurismo religioso lo que Gayle Rubin llama "pánico moral" (Rubin, 1989). Bajo esta idea, se asume que cualquier ruptura de las fronteras que separan la sexualidad heteronormada del resto de las sexualidades, desencadenaría consecuencias que llevarían a la autodestrucción social. Así, el discurso opositor al matrimonio "igualitario" refuerza la norma de género obligatoria que dicta quiénes pueden o no aparecer en el espacio público, y cuáles son las condiciones para ser reconocido/a en dicha esfera. Como dice Judith Butler (2009), la relegación al espacio privado de las personas que no se ajustan a los cánones de la heterosexualidad, reproduce el mandato heterosexual que las hace ininteligibles en el ámbito público.

Emerge acá un elemento central en el discurso del conservadurismo religioso, que se articula con la noción de la ecología humana. Esto es lo que podría denominarse la "lógica de la contaminación y el contagio". Esta lógica reproduce un modelo heredado del proceso colonialista europeo del siglo XIX, donde el/la colonizado/a era visto/a desde Europa como el/la portador/a de toda enfermedad (física, mental o moral) comunicable. Esta condición, justificaba el proyecto colonialista de higienización del mundo colonial. Así, esta construcción de la alteridad eurocentrada admitió la creación de barreras para restringir los contactos con el/la colonizado/a, entendido/a como un/a enfermo/a que suponía la portación de males cuyo contagio debía impedirse. ${ }^{10}$

Siguiendo esto, se hace posible trazar un paralelismo con la lógica que atraviesa el argumento ecológico del conservadurismo religioso cordobés en su rechazo a la modificación del Código Civil. La resistencia al matrimonio "igualitario" asume la idea de que al modificarse la ley, el Estado no solo permitiría que las parejas del mismo sexo puedan contraer matrimonio, sino además promovería expresiones no heterosexuales en la población. En este sentido se expresaba un activista frente al Senado de la Nación:

La ley tiene una sensación de ejemplaridad [...]. En este contexto les digo: cuando a los niños se les diga que es tan válido un matrimonio como el otro, ¿con quiénes se van a identificar? Un día querrán casarse con un hombre y al otro con una mujer. Es muy grave lo que están haciendo (activista conservador religioso, Córdoba, 2010)

De este modo, el conservadurismo religioso construye un Otro contaminado, no-humano, enfermo, anormal, exigiendo al Estado confinarlo a los límites del ámbito privado a fin de evitar el contagio de su condición hacia la población "sana". La argumentación de la ecología humana se presenta así como un aparato higienista, mediante el cual se produce el/ la sujeto/a no heterosexual enfermo/a, y en donde el Estado debe asumir un rol sanitario de protección de la población heterosexual "sana". ${ }^{11}$

10. Roberto Cardoso de Oliveira (2007), por ejemplo, relata cómo la discriminación de los pueblos originarios llegó a tal punto en algunas zonas de Brasil de la primera mitad del siglo XX, que se segregaba a sus niños/as a escuelas separadas de las escuelas de los/as hijos/as de los/as demás habitantes de la región, ante el temor de contagio de las "impurezas" de los/as tukuna.

11. La lógica de la contaminación y el contagio no es algo nuevo en el campo de la sexualidad. Como lo ha indicado Beatriz Preciado (2002), esta sirvió de base también para la patologización del tacto y la consecuente producción de tecnologías orientadas a la contención de la masturbación en la Europa clásica. 


\section{La familia y el atentado contra la nación argentina}

La idea de lo natural que circunscribió el discurso opositor al matrimonio "igualitario", fue articulado además con otros dos conceptos que fueron centrales en los argumentos del conservadurismo religioso cordobés: la familia y la nación. La familia fue recurrentemente significada de maneras específicas, a fin de defender la idea de una identidad nacional común fundada sobre la base de la familia heterosexual, identidad que debía ser defendida respecto de la amenaza que constituiría el matrimonio "igualitario".

Como hemos visto, el discurso conservador religioso asume la idea de que la única familia legítima, de acuerdo a los cánones dictados por la naturaleza sexual heteronormada, es aquella fundada sobre la relación entre un hombre y una mujer. Siendo que la "misión" del matrimonio, entendido siempre como heterosexual, supone la reproducción de la especie, estos sectores sitúan a la familia conyugal como el dispositivo clave de la existencia de la sociedad, ya que solo esta promovería la reproducción humana necesaria para la vida en sociedad. La familia, así entendida, sería el núcleo de la sociedad. Como indicaba una activista frente al Senado Nacional en el marco de la discusión por el matrimonio "igualitario": "todo lo que hacemos es en defensa de la familia, considerándolo un bien inalterable, un bien irrenunciable de nuestra sociedad. Todo esto es porque venimos de una familia" (activista conservadora religiosa, Córdoba, 2010).

La defensa de "la" familia sostenida desde estos sectores, produce una homogeneización del concepto, asumiendo una noción monolítica que elimina toda referencia a constituciones familiares alternativas. Desde esta perspectiva, la familia se vincula únicamente con el matrimonio heterosexual, lo que supone que toda unión entre personas del mismo sexo queda por fuera de la idea de familia inteligible desde el discurso conservador religioso. Las familias basadas en uniones no heterosexuales, en otras palabras, representan el exterior de "la" familia.

Pero la familia heterosexual no solo es comprendida por estos sectores como una mera institución de reproducción biológica. "La" familia también es asumida como un dispositivo identitario mediante el cual se forjaría la identidad nacional argentina (Sgró Ruata, 2011). En otras palabras, la nacionalidad es comprendida como una identidad instituida sobre la familia heterosexual, y por tanto, cualquier amenaza a la hegemonía de la heterosexualidad y de las insti- tuciones que la soportan, como el matrimonio entre un hombre y una mujer, constituye una amenaza directa en contra de la nación y de la propia identidad argentina. En estos términos expresó un activista del movimiento conservador religioso cordobés frente a la Comisión de Legislación General del Senado de la Nación en Córdoba:

la familia es la matriz de un pueblo, de una nación, con ello no se improvisa [...]. Al pueblo de la nación le están por cambiar su matriz de vida y es el convidado de piedra, pero el pueblo cobra, de esta no se sale gratis. El corifeo de las minorías, el corifeo de los grupos interesados no podrá ir en contra de la decisión general del pueblo de la nación (activista conservador religioso, Córdoba, 2010).

En la misma instancia, otra activista decía:

Somos un pueblo que viene asentado en la familia desde siempre; creo que ustedes tienen la posibilidad de levantar la mano y destruirnos como pueblo argentino o no hacerlo sin ser omisivos y acertados en su posturas (activista conservadora religiosa, Córdoba, 2010).

La significación de la nación realizada desde el conservadurismo religioso, representa un mecanismo de inclusión/exclusión que limita las expresiones sexuales en función de la familia heterosexual. En este sentido, los argumentos apelan a la noción de una "verdadera nación", una nación que comulga con valores específicos que se oponen radicalmente a las demandas formuladas desde los movimientos por la diversidad sexual (consideradas por los sectores conservadores religiosos como anti-valores). Las expresiones no heterosexuales de algunos/as argentinos/as y las demandas políticas que se articulan en torno a estas suponen así para el conservadurismo religioso un riesgo para la hegemonía de los valores tradicionales configurados en torno a "la" familia, lo que las convierte en prácticas antipatrióticas, verdaderos atentados contra la nación.

Siguiendo a Benedict Anderson, "la nacionalidad o la 'calidad de nación' [...], al igual que el nacionalismo, son artefactos culturales de una clase particular" (Anderson, 1991, p. 21), y no entidades con una esencia propia. ${ }^{12}$ Toda construcción de una "nación" es imaginada como una entidad limitada, con fronteras finitas, soberana y asociada a una comunidad. La comunidad, en este sentido, no representa una unidad "verdadera", sino que es igualmente imaginada y producida como una entidad limitada y uni-

12. De este modo, Anderson, así como otros/as autores vinculados/as a los estudios poscoloniales, ponen en duda la idea de la identidad como un concepto que responde a un cierto estado de cosas, abriendo el paso a posturas antiesencialistas que permiten desnaturalizar e historizar la alteridad (Briones, 2007). 
forme. De este modo, como señalan Michael Hardt y Antonio Negri (2006), la construcción de la nación tiende a borrar las desigualdades y el pluralismo vivo en el interior de sus límites discretos, produciendo la ilusión de una unidad homogénea.

Al articular la idea de nación con la de la familia heterosexual, el conservadurismo religioso borra así la pluralidad propia de la población que integra el territorio nacional, instituyendo una jerarquía sexual (Rubin, 1989) que establece no solo la heterosexualidad como la única sexualidad legítima, sino además como un modelo nacional de sexualidad obligatoria.

Los discursos y dispositivos que han tendido a homogeneizar a la nación como una ilusión de esencia indivisible no son nuevos en Argentina. Como indica Rita Laura Segato, estos esfuerzos datan de un modelo impuesto por el Estado a lo largo de los siglos XIX y XX para hacer frente a las amenazas de rupturas sostenidas por la fractura capital/interior y por el fuerte contingente de inmigración europea ocurrido en esos siglos (Segato, 1998). Heredando este modelo, el conservadurismo religioso cordobés, en su oposición al matrimonio "igualitario", apela así a una serie de argumentos que producen una virtual homogeneización de la nación sobre la base de la familia heterosexual. El discurso construye una homogeneidad nacional que, siguiendo a Eric Hobsbawm, responde a un aparato más propagandístico o programático que a un interés realmente descriptivo (Hobsbawm, 1998).

Siguiendo este modelo, el conservadurismo religioso genera un desplazamiento respecto del tradicional vínculo establecido por la elite argentina de principios del siglo XX entre nación y catolicismo, hacia un anudamiento entre nación y heterosexualidad. Ante la confluencia entre la masa inmigrante y la población criolla, la elite política de aquella época asumió la necesidad de construir la nación en torno a una unidad común. Entendiendo la religión católica como un común denominador poblacional entre criollos e inmigrantes, el catolicismo fue promovido como un eje identitario nacionalista (Di Stefano y Zanatta, 2009). Pero en los discursos que circularon el 2010 en torno a la discusión sobre el matrimonio "igualitario", el conservadurismo religioso desplazó a la religión de ese eje, reemplazándolo por la idea de la familia heterosexual. Por supuesto, esto no significa que la idea de la "nación católica" no haya rondado los discursos de estos sectores durante la discusión de la ley. Antes bien, este fenómeno debe interpretarse como una estrategia discursiva secular que tendió a acentuar la idea de una "nación heterosexual" por sobre la de una "nación católica", con el fin de lograr una mayor incidencia política al despojarse de idearios religiosos (Vaggione, 2005). En otras palabras, este no es un desplazamiento que suponga una ruptura entre ambas nociones, sino más bien una conti- nuidad donde lo que se acentúa ahora no es tanto la idea religiosa de una identidad católica, sino la de una constitución identitaria fundada en la familia conformada por un hombre y una mujer.

La homogeneización del ideario nacional que establece el discurso conservador religioso con base en la sexualidad resulta coherente con el concepto de "fundamentalismo cultural", aplicado por Verena Stolcke (2004) en su análisis de las políticas anti-inmigratorias en Europa. La autora propone este concepto para referirse a aquellos discursos que justifican posturas nacionalistas excluyentes teniendo como blanco a los/as sujetos inmigrantes. Bajo argumentaciones que fortalecen la idea de una homogeneidad nacional con fronteras discretas, el fundamentalismo cultural establece límites esencialistas respecto de otras culturas o nacionalidades que supondrían una amenaza para el bienestar y la estabilidad de las sociedades destinatarias de los flujos migratorios.

De modo análogo, la fusión conservadora religiosa entre la nación imaginada y la familia heterosexual, demarca las fronteras entre las prácticas e identidades que supuestamente serían propiamente nacionales y aquellas que, a pesar de cohabitar el mismo territorio, atentarían contra la identidad y valores de la nación. El binomio "familia heterosexual-nación" funda así una suerte de fundamentalismo cultural que sirve de justificación ideológica para un nacionalismo excluyente inspirado en la idea del Estado-nación que implica, como señala Stolcke, "un artificio político histórico circunscrito a un pueblo = nación, concebido como culturalmente homogéneo y singular, anclado en la tradición y en la historia" (Stolcke, 2004: 27). La homosexualidad, el lesbianismo y la bisexualidad suponen así expresiones que, en el discurso conservador religioso, se posicionan por fuera de los márgenes de la identidad nacional y del pueblo argentino. Con esto, se establece una "extranjerización" de los movimientos por la diversidad sexual y sus demandas, a partir de la cual se las asocia a realidades foráneas que buscan erosionar los principios nacionales del Estado-nación argentino (Vaggione, 2009b). En este sentido, toda expresión de género y sexualidad no heterosexual queda producida como un Otro por fuera de la cultura nacional.

La insistencia del conservadurismo religioso se basa en el temor de que se institucionalice una nueva cultura nacional donde la familia heterosexual ya no sea promovida por las instituciones y la ley como el pilar básico de la sociedad. El fundamentalismo cultural inscrito en los argumentos del conservadurismo religioso cordobés supone la delimitación de una cultura fundacional que debe ser defendida. Siguiendo esta lógica se expresaba un ponente conservador cordobés ante la Comisión de Legislación General del Senado de la Nación en Córdoba: 
La fuerza de sus principios y valores éticos están fuertemente enraizados en la cultura familiar, que es la cultura de todos los cordobeses. No se deje robar esta herencia por intereses ajenos y hostiles a ella; no permita que nos roben las aspiraciones nobles del varón y la mujer, la ética fundada en la verdad y los valores de la persona digna [...]. Póngase de pie ante esta situación, acomode sus bolsas, mire nuestra herencia y nuestro horizonte como nación (activista conservador religioso, Córdoba, 2010).

La cultura opera acá de un modo similar al que resalta Abu-Lughod (1991) en su crítica a este concepto. Según la autora, el uso de la noción de cultura supone un efecto de homogeneización, coherencia y atemporalidad que aplana las diferencias, produciendo una idea de una entidad delimitada por fronteras discretas. Del mismo modo, la idea de una cultura nacional basada en la estructura familiar heterosexuada tiende a borrar las diferencias que se dan en el interior del territorio nacional, donde cohabitan estructuras familiares diversas, basadas tanto en la heterosexualidad como en otras formas no heterosexuales de convivencia y sexualidad.

\section{Reflexiones finales}

Si bien el movimiento conservador religioso cordobés se ha abocado históricamente a trabajar fuertemente temáticas como el aborto y la anticoncepción hormonal de emergencia, la inclusión del matrimonio "igualitario" en la agenda política, y en particular en la agenda legislativa, motivó la rearticulación de este sector a fin de organizar una oposición a la iniciativa.

Un primer eje del discurso conservador religioso se estableció con base en la defensa de valores en- tendidos como universales, anclados en la naturaleza del ser humano. Esta idea articuló una batería de argumentos que situó su foco en torno a una noción reproductiva de la sexualidad, cuya consumación se alcanzaría en la institución matrimonial. Así, en su oposición al matrimonio "igualitario", el conservadurismo religioso representó una compleja trama de elementos que intentaron circunscribir lo natural y lo humano a un modelo de sexualidad anclado en la idea del dimorfismo sexual y la heterosexualidad.

Los argumentos esgrimidos desde acá denotaron construcciones que articularon el binomio familianación como un segundo eje central en la oposición a la modificación legal. La noción de la familia heterosexual reproductiva, asumida como un elemento fundacional de la nación argentina, supuso desde el conservadurismo religioso la idea de que cualquier cambio que desarticulase la hegemonía del matrimonio entre un hombre y una mujer implicaría un directo atentado contra las bases de la nación y la identidad nacional.

La aprobación del matrimonio "igualitario" abre nuevos escenarios e interrogantes para el conservadurismo religioso cordobés. Vale la pena preguntarse cómo responderán al "atentado" que supuso el matrimonio "igualitario" para la naturaleza y la identidad nacional, tal como estos sectores lo interpretan. Posiblemente, surjan nuevas articulaciones y discursos que busquen revertir la sanción legislativa, así como nuevos espacios de movilización que será necesario observar con atención. ¿Rearticulará el movimiento conservador sus estrategias a fin de lograr revertir la decisión legislativa? O, por otro lado, ¿será ésta asumida como una derrota, procurando ahora redoblar sus esfuerzos para proteger el tema que ha sido medular en los últimos años para este sector, esto es, la protección de la vida humana desde la fecundación?

\section{Referencias}

ABU-LUGHOD, Lila. Writing against culture. In: FOX, Richard (ed.). Recapturing anthropology: Working in the present. Santa Fe, New Mexico: School of American Research Press, 1991.

ANDERSON, Benedict. Comunidades imaginadas. Mexico, D.F.: Fondo de Cultura Económica, 1991.

BECERRA DOS SANTOS, Josadac. Pós-estruturalismo, religião e democracia: notas sobre aportes teóricos do deslocamento do político para a subjetividade. Sociedade e Cultura, vol. 7, n. 1, p. 37-47, 2004.

BRIONES, Claudia. Teorías performativas de la identidad y performatividad de las teorías. Tabula Rasa, n. 6, p. 5583, 2007.
BUTLER, Judith. Deshacer el género. Barcelona: Paidós, 2006.

. El género en disputa. El feminismo y la subversión de la identidad. Barcelona: Paidós, 2007.

. Performatividad, precariedad y políticas sexuales. AIBR. Revista de Antropología Iberoamericana, vol. 4, n. 3, p. 321-336, 2009.

CARBONELLI, Marcos; IRRAZÁBAL, Gabriela. Católicos y Evangélicos. ¿Alianzas Religiosas en el campo de la bioética? Nómadas. Revista Crítica de Ciencias Sociales y Jurídicas, vol. 26, n. 2, 2010. Disponible en: http://ebrels. files.wordpress.com/2010/10/carbonelli_irrazabal.pdf Acceso em: 22 abr. 2012. 
CARDOSO DE OLIVEIRA, Roberto. Etnicidad $y$ estructura social. Mexico, D.F.: Centro de Investigaciones y Estudios Superiores en Antropología Social / Universidad Autónoma Metropolitana / Universidad Iberoamericana, 2007.

DI STEFANO, Roberto; ZANATTA, Loris. Historia de la Iglesia Argentina. Desde la Conquista hasta fines del siglo XX. Buenos Aires: Sudamericana, 2009.

DIDES, Claudia. Voces en emergencia: el discurso conservador y la píldora del día después. Santiago de Chile: FLACSO, 2006.

FAUSTO-STERLING, Anne. Cuerpos sexuados. La política de género y la construcción de la sexualidad. Barcelona: Melusina, 2006.

HALPERIN, David. San Foucault. Buenos Aires: Ediciones Literales, 2007.

HARDT, Michael; NEGRI, Antonio. Imperio. Buenos Aires: Paidós, 2006.

HILLER, Renata. Lazos en torno a la Unión Civil. Nota sobre el discurso opositor. In: PECHENY, Mario; FIGARI, Carlos; JONES, Daniel (comp.). Todo sexo es político. Buenos Aires: Libros del Zorzal, 2008.

HOBSBAWM, Eric. Naciones y nacionalismo desde 1780. Barcelona: Crítica, 1998.

JONES, Daniel; AZPARREN, Ana Laura; POLISCHUK, Luciana. Evangélicos, sexualidad y política. Las instituciones evangélicas en los debates públicos sobre unión civil y educación sexual en la Ciudad Autónoma de Buenos Aires (2003 - 2004). In: VAGGIONE, Juan Marco (comp.). El activismo religioso conservador en Latinoamérica. Córdoba: Ferreyra Editor / Católicas por el Derecho a Decidir, 2010.

MORÁN FAÚNDES, José Manuel. De patologías y terapias: el discurso científico del conservadorismo religioso sobre la sexualidad y el cuerpo. In: PEÑAS DEFAGO, María Angélica; VAGGIONE, Juan Marco (comp.). Actores $y$ discursos conservadores en los debates sobre sexualidad y reproducción en Argentina. Córdoba: Ferreyra Editor / Católicas por el Derecho a Decidir, 2011.

MUjICA, Jaris. Economía política del cuerpo. La reestructuración de los grupos conservadores y el biopoder. Lima: Promsex, 2007.

PEÑAS DEFAGO, María Angélica. Los estudios en bioética y la Iglesia Católica en los casos de Chile y Argentina. In: VAGGIONE, Juan Marco (comp.). El activismo religioso conservador en Latinoamérica. Córdoba: Ferreyra editor / Católicas por el Derecho a Decidir, 2010. PRECIADO, Beatriz. Manifiesto contra-sexual. Madrid: Opera Prima, 2002.

Multitudes queer. Notes pour une politique des 'anormaux'. Multitudes, n. 12, 2003. Disponible en: http:// multitudes.samizdat.net/Multitudes-queer. Acesso em: 10 abr. 2012.

RABBIA, Hugo H.; IOSA, Tomás. Plazas multicolores, calles naranjas. La agenda del matrimonio entre parejas del mismo sexo en el activismo LGTB cordobés y la oposición religiosa organizada. In: SGRÓ RUATA, María Candelaria et al. El debate sobre matrimonio igualitario en Córdoba. Actores, estrategias y discursos. Córdoba: Ferreyra Editor / Católicas por el Derecho a Decidir, 2011. RATZINGER, Joseph. Lo que cohesiona el mundo. Los fundamentos morales y prepolíticos del Estado liberal. In: HABERMAS, Jürgen; RATZINGER, Joseph. Entre razón y religión. Dialéctica de la secularización. Mexico, D.F.: Fondo de Cultura Económica, 2008.

RICH, Adrienne. Compulsor y heterosexuality and lesbian existence. In: RICH, Adrienne. Blood, Bread, and Poetry. Nueva York: Norton Paperback, 1994.

ROSADO-NUNES, Maria José. O catolicismo sob o escrutínio da modernidade. In: MUNIZ, Beatriz; MARTINIO, Luiz Mauro (org.). Sociologia da religião $e$ mudança social: Católicos, protestantes e novos movimentos religiosos no Brasil. São Paulo: Paulinas, 2004.

ROSTAGNOL, Susana. Disputas sobre el control de la sexualidad: Activismo religioso conservador y dominación masculina. In: VAGGIONE, Juan Marco (comp.). El activismo religioso conservador en Latinoamérica. Córdoba: Ferreyra Editor / Católicas por el Derecho a Decidir, 2010. RUBIN, Gayle. Reflexionando sobre el sexo. Notas para una teoría radical de la sexualidad. In: VANCE, Carole (comp.). Placer y peligro. Explorando la sexualidad femenina. Madrid: Revolución, 1989.

SEGATO, Rita Laura. Alteridades históricas/identidades políticas: una crítica a las certezas del pluralismo global. Brasilia: Universidade de Brasília, Departamento de Antropologia, 1998.

SGRÓ RUATA, María Candelaria. Matrimonio entre personas del mismo sexo. Estrategias político discursivas de oposición en la Audiencia Pública de Córdoba. In: SGRÓ RUATA, María Candelaria et al. El debate sobre matrimonio igualitario en Córdoba. Actores, estrategias y discursos. Córdoba: Ferreyra Editor / Católicas por el Derecho a Decidir, 2011.

STOLCKE, Verena. Qué entendemos por integración social de los inmigrantes. In: CHECA, Francisco; CHECA, Juan Carlos; ARJONA, Ángeles (eds.). Inmigración $y$ derechos humanos. La integración como participación social. Barcelona: Icaria, 2004.

VAGGIONE, Juan Marco. Reactive Politicization and Religious Dissidence: The Political Mutations of the Religious. Social Theory and Practice, vol. 31, n. 2, p. 165188, 2005.

La sexualidad en el mundo post secular. El activismo religioso y los derechos sexuales y reproductivos. In: GERLERO, Mario Silvio (coord.). Derecho a la Sexualidad. Buenos Aires: Grinberg, 2009a.

Sexualidad, Religión y Política en América Latina. In: Diálogo Latinoamericano sobre Sexualidad y Geopolítica, 2009b, Río de Janeiro. Disponible en: http://www.sxpolitics.org/pt/wp-content/uploads/2009/10/sexualidad-religion-y-politica-en-america-latina-juan-vaggione.pdf Acesso em: 09 mar. 2012. 
Prólogo. El activismo religioso conservador en América Latina. In: (comp.). El activismo religioso conservador en Latinoamérica. Córdoba: Ferreyra Editor / Católicas por el Derecho a Decidir, 2010.
WYNARCZYK, Hilario. Partidos políticos evangélicos conservadores bíblicos en la Argentina. Formación y ocaso 1991 - 2001. Civitas, vol. 6, n. 2, p. 11-41, 2006.

\title{
Sexuality and alterity: the arguments of religious conservatism in Cordova against same-sex marriage
}

\begin{abstract}
In 2010 Argentina passed a law that amended the Civil Code, allowing same-sex couples to get married. During the legislative debate, various conservative sectors publicly argued along to prevent the legal reform. In Cordova, the conservative mobilization was widely visible, and its discourses circulated in various public spaces, reaching even national notoriety. Taking this into consideration, this article analyzes the arguments of the religious conservative movement of Cordova, placing special emphasis on the construction of otherness made by these sectors through the ideas of nation, family and nature. Based on these lines, I consider the discursive articulations that linked non-heterosexual expressions with the idea of an Other, understood as the antithesis of nature and national identity.
\end{abstract}

Key-words: sexuality, marriage, nature, nation, Cordova.

\section{Sexualidade e alteridade: os argumentos do conservadorismo religioso em Córdoba contra o casamento entre pessoas do mesmo sexo}

\section{Resumo}

Na Argentina, no ano 2010, foi aprovada a lei que modificou o Código Civil, permitindo o casamento entre pessoas do mesmo sexo. Durante esse período de discussão legislativa diversos setores conservadores esgrimiram publicamente argumentos para evitar a aprovação da lei. Em Córdoba, a mobilização desses grupos foi amplamente visível e seus discursos circularam por diferentes espaços públicos, alcançando notoriedade até no âmbito nacional. Levando estes fatos em consideração, o presente artigo analisa os argumentos utilizados pelo movimento conservador religioso cordobês, colocando especial ênfase nas construções da alteridade sustentadas a partir das ideias de nação, família e natureza. Partindo desses eixos, serão avaliadas as articulações argumentais que procuraram vincular as expressões não heterossexuais com a noção do Outro, entendido como antítese do natural e da identidade nacional.

Palavras-chave: sexualidade, casamento, natureza, nação, Córdoba. 